\title{
Bacterial Host Interactions in Cystic Fibrosis
}

\author{
Máire Callaghan \\ Institute of Technology Tallaght, maire.callaghan@tudublin.ie \\ Siobhan McClean \\ Institute of Technology Tallaght, Siobhan.mcclean@tudublin.ie
}

Follow this and additional works at: https://arrow.tudublin.ie/ittsciart

Part of the Biochemistry Commons, Cell Biology Commons, Microbiology Commons, Molecular Biology Commons, and the Other Immunology and Infectious Disease Commons

\section{Recommended Citation}

Callaghan, $\mathrm{M}$ and Mcclean, S. Bacterial host interactions in cystic fibrosis. Current opinion in microbiology. 12/2011; 15(1):71-7. DOI:10.1016/j.mib.2011.11.00

This Article is brought to you for free and open access by the School of Science and Computing at ARROW@TU Dublin. It has been accepted for inclusion in Articles by an authorized administrator of ARROW@TU Dublin. For more information, please contact

arrow.admin@tudublin.ie, aisling.coyne@tudublin.ie, gerard.connolly@tudublin.ie.

Funder: PRTLI Cycle 4

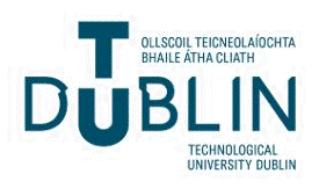




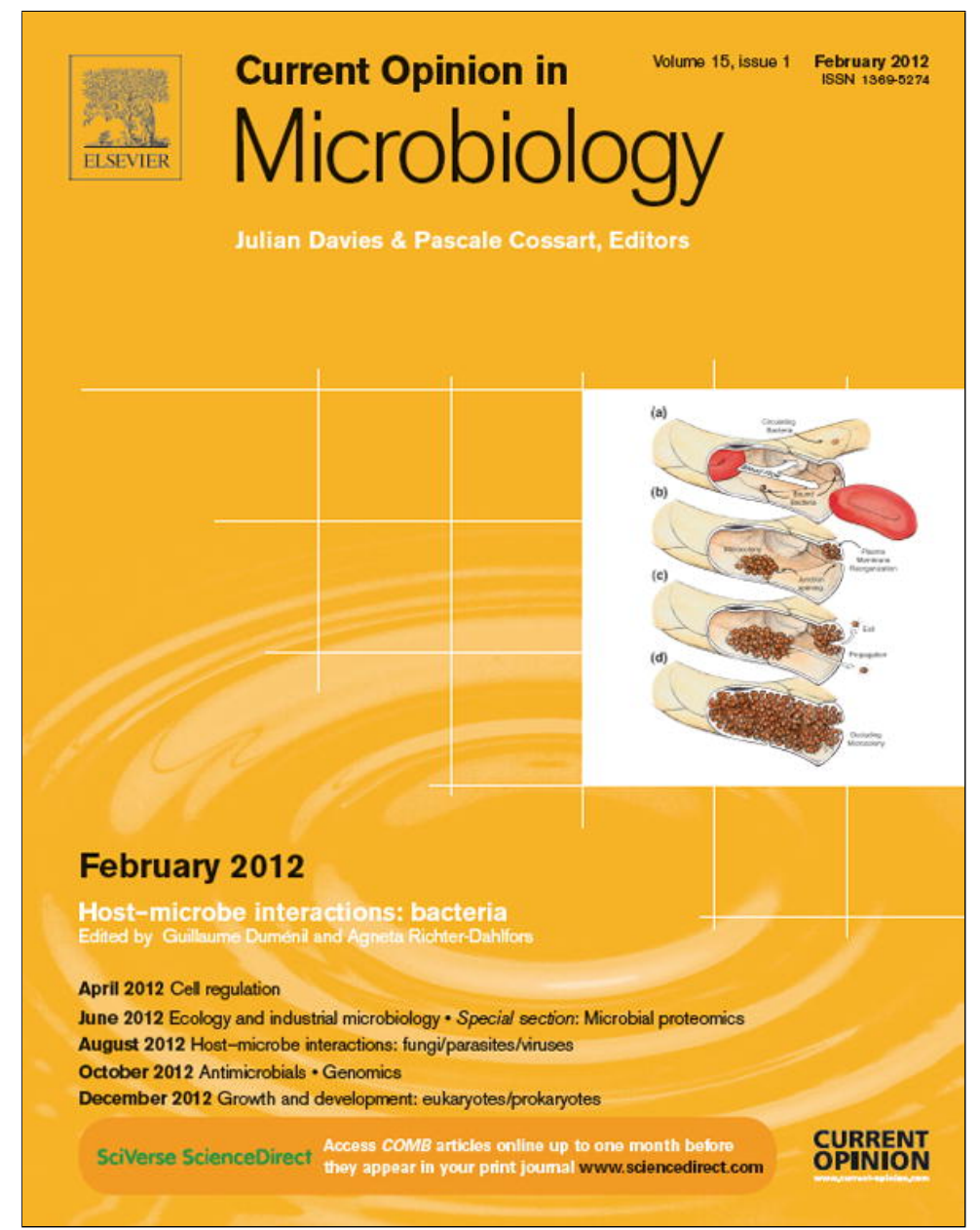

This article appeared in a journal published by Elsevier. The attached copy is furnished to the author for internal non-commercial research and education use, including for instruction at the authors institution and sharing with colleagues.

Other uses, including reproduction and distribution, or selling or licensing copies, or posting to personal, institutional or third party websites are prohibited.

In most cases authors are permitted to post their version of the article (e.g. in Word or Tex form) to their personal website or institutional repository. Authors requiring further information regarding Elsevier's archiving and manuscript policies are encouraged to visit:

http://www.elsevier.com/copyright 


\section{Bacterial host interactions in cystic fibrosis Máire Callaghan and Siobhán McClean}

\begin{abstract}
Chronic infection is a hallmark of cystic fibrosis (CF) and the main contributor to morbidity. Microbial infection in CF is complex, due to the number of different species that colonise the CF lung. Their colonisation is facilitated by a host response that is impaired or compromised by highly viscous mucous, zones of hypoxia and the lack of the cystic fibrosis transmembrane regulator (CFTR). Successful dominant CF pathogens combine an effective arsenal to establish infection and counter-attack the host response, together with an ability to adapt readily to an unfavourable environment.

Hypermutability is common among CF pathogens facilitating adaptation and as the host response persists, progressive destruction of the normal architecture of lung tissue ensues with catastrophic consequences for the host.
\end{abstract}

\section{Address}

Centre of Microbial Host Interactions and Centre of Applied Science for Health, Institute of Technology Tallaght, Tallaght, Dublin 24, Ireland

Corresponding author: McClean, Siobhán (Siobhan.mcclean@ittdublin.ie)

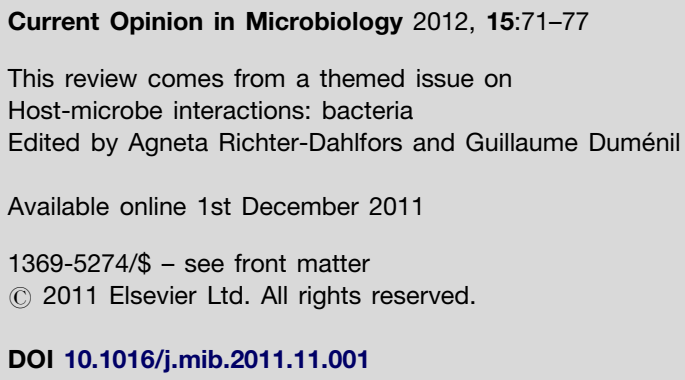

\section{Introduction}

Cystic fibrosis is caused by mutations in the CFTR gene leading to a disrupted chloride channel. It is well established that the greatest contributor to patient morbidity and mortality is chronic lung disease, caused by a constant cycle of infection and inflammation throughout the patient's life (Figure 1). The CF'TR mutation leads to defective regulation of chloride and sodium, resulting in increased water absorption, depletion of airway surface liquid (ASL) and dehydrated mucous $\left[1^{\bullet}\right]$. Consequently, the purulent sputum and mucus plugs together with an ineffective inflammatory response, all contribute to the chronic infections that are central to $\mathrm{CF}$ lung disease.

From early childhood, CF patients experience recurrent pulmonary infections from a range of pathogens. In spite of intensive antibiotic therapy, certain organisms persist, leading to pulmonary exacerbations, hospitalizations and patient death (Box 1). These include Pseudomonas aeruginosa, Burkholderia cepacia complex (Bcc) and Achromobacter xylosoxidans $\left[2^{\circ}\right]$, with Bcc being the most problematic. It was recently demonstrated that chronic colonisation by Bcc resulted in a greater lung function decline than by the other two pathogens [3]. CF patients are also susceptible to colonisation by other pathogens, including Staphylococcus aureus (both Methicillin-resistant and sensitive), genus Pandoraea, Stenotrophomonas maltophilia and non-tuberculous Mycobacteria (NTM) [4-6] although the role of these latter four pathogens in CF lung disease is unclear. For example, a recent paper investigating 21 patients colonised with $S$. maltophilia without any other Gram negative organism, showed that there was a comparable decline in lung function in the two years after colonisation, to the three years before its identification [6]. Furthermore, the identification of high levels of anaerobic organisms in CF sputum [7] has added to the complex microbial population in the CF lung. These CF-associated anaerobes were not susceptible to antibiotics with known efficacy against anaerobes and the clinical significance of anaerobes in CF is not yet fully understood [8]. Limited information exists on the host-microbial interactions of many of these organisms and this review will focus only on the current understanding of the more clearly defined CF pathogens (Box 1)

\section{Role of CFTR in CF lung colonisation}

A direct role of the CFTR mutation in CF pathogenesis has been attributed to normal CFTR acting as a pathogen receptor involved in the internalisation and subsequent clearance of $P$. aeruginosa [9], but this mechanism is pathogen-specific. Mutated CFTR has also been attributed to be the cause of reduced internalisation of one Bcc species, Burkholderia dolosa, but not the more virulent Burkholderia cenocepacia in respiratory epithelial cells [10]. Furthermore, in contrast to $P$. aeruginosa, $S$. aureus was more invasive of CF cells compared to non-CF cells [11], indicating that CFTR is not the only route of bacterial uptake and invasion into the epithelium.

Alterations in the phenotype of CF airway epithelial cells also provide receptors for pathogens to adhere to. For example, $\mathrm{CF}$ airways show alterations in membrane glycoproteins and glycolipids which are directly linked to the CFTR defect (reviewed by [12]). The ratio of asialylated to sialylated glycolipids is higher in CF cells compared to non-CF cells, providing additional receptors for $P$. aeruginosa and Bcc. This is significant as invasion of lung epithelial cells by Bcc depends on asialylated glycolipids [13]. In addition, alterations in specific fucosyl residues of 


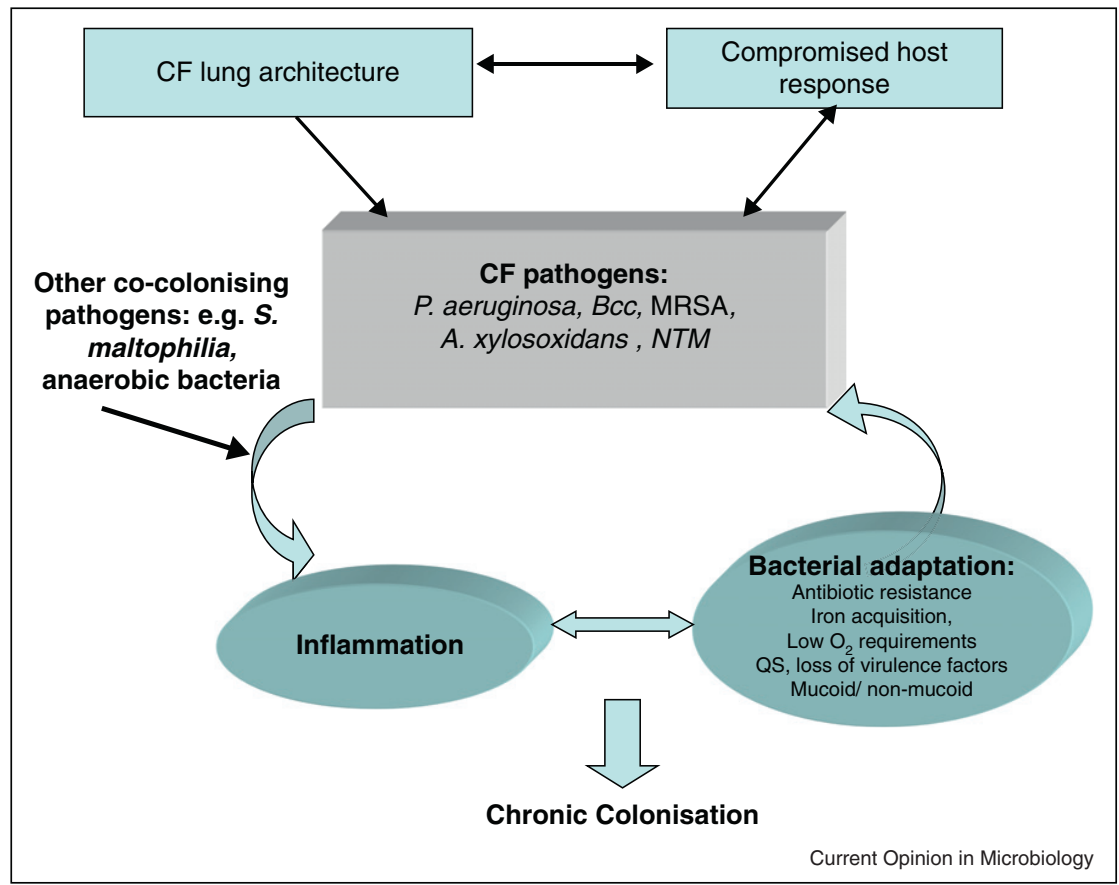

The cycle of infection and inflammation combined with bacterial adaptation allows bacteria to chronically colonise the CF host.

Box 1 Examples of bacteria isolated from CF lung and their contribution to CF lung disease

\section{Definite pathogen in CF}

P. aeruginosa

Burkholderia cepacia complex (particularly B. cenocepacia)

Methicillin resistant Staphylococcus aureus

Likely pathogen in CF

Achromobacter xyloxidans

Non-tuberculous Mycobacteria

Unclear role in CF lung disease

Genus Pandoraea

Methicillin sensitive Staphylococcus aureus

Inquilinus limosus

Ralstonia species

Haemophilus influenzae

Anaerobic bacteria (e.g. Prevotella sp., Bacteroides sp., Porphyromonas sp.)

Unlikely pathogen in CF

Stenotrophomonas maltophilia membrane glycopeptides of CF cells provide receptors for a fucose-specific $P$. aeruginos a lectin that is involved in $P$. aeruginosa pathogenicity [14]. Furthermore, increased glycosaminoglycan levels have been observed in CF airways as recently reviewed by Reeves $e t$ al. [15] and may contribute to CF lung disease. For example, increased heparan sulphate prolongs the efficacy of cytokines, such as interleukin (IL)-8, and also acts as a receptor for $P$. aeruginosa. Finally, it has recently been shown that CFTR deficiency in mice led to a reduction in acid sphingomyelinase activity, allowing ceramide accumulation in lung tissue $\left[16^{\bullet \bullet}\right]$. The elevated ceramide resulted in increased cell death and subsequent deposition of DNA in the respiratory tracts, providing sites for $P$. aeruginosa attachment [16]. This accumulation of ceramide was also observed in CF patients and the treatment of a $\mathrm{CF}$ patient with the acid sphingomyelinase inhibitor, amitriptyline resulted in a greater than $10 \%$ improvement in lung function [17].

\section{The host immune response in the CF lung}

The airway epithelium recognizes and responds to pathogens through the interaction between host pathogen recognition receptors and pathogen-associated membrane proteins. Toll like receptors (TLRs) such as TLR-4 on epithelial surfaces interact with lipopolysaccharide resulting in the activation of cytokine and anti-microbial peptide genes. TLR-2 signaling by $P$. aeruginosa has been shown to initiate cleavage of intracellular junctional 
proteins to accommodate neutrophil transmigration [18]. The neutrophils while important in pathogen clearance, undergo necrosis resulting in DNA release and increased mucous viscosity, compounding the problem of bacterial attachment. Another aspect of host defense that is compromised in CF is macrophage clearance of pathogens. Recent evidence suggests that dysfunctional CFTR in macrophages impairs bacteriocidal activity against $P$. aeruginosa [19], but the specific role of CFTR in macrophage killing remains undefined and controversial. Many humoral components of immunity are also ineffective in CF. Host defense peptides (HDPs) are impaired due to the dehydrated mucous of the ASL [1] and secretion of proteases in the CF lung further compromises immune function. In particular, neutrophil elastase predominates and in addition to destroying a range of anti-microbial proteins, degrades mucin [20] and increases IL-8 secretion from epithelial cells [21]. This is significant because Bcc strains have enhanced growth in the presence of IL-8 [22]. Dysregulation of matrix metalloproteases (MMPs) in CF is another contributor to $\mathrm{CF}$ lung disease and to bacterial colonisation. Adult CF patients show elevated levels of serum MMP-1, MMP-8 and MMP-9 [23] and elevated MMP-9 in lower airway secretions [24]. Recently, we have shown that while $P$. aeruginosa predominantly activates MMP-2 in CF lung epithelial cells, B. cenocepacia infection activated MMP-9 only, the latter resulting in a delay in wound healing [25].

The host response in $\mathrm{CF}$ may be further affected by gender. Female CF patients have poorer survival rates than males. This has been attributed to estradiol reducing the ASL volume of CF epithelia in vitro [26]. More recently, treatment of $P$. aeruginosa-infected male CFTR-knockout mice with $17 \beta$-estradiol resulted in an increased secretion of pro-inflammatory-chemokines and chemoattractant-chemokines compared to controls [27], indicating that estrogens also have a direct effect on host response. Many of the elevated cytokines were Th17mediators, which is significant in the context of the IL-23/ IL-17 dependence of neutrophil recruitment during $P$. aeruginosa infection [28]. A 99\% reduction in lactoferrin mRNA and a higher lung bacterial burden, was also observed in estrogen treated mice, relative to the control group. Many aspects of the host response in $\mathrm{CF}$ are therefore either impaired or dysregulated by chronic infection and may be further modulated by hormones, with potential significant consequences for the host.

\section{Adaptation of bacterial pathogens to the CF lung}

Adaptations of CF pathogens facilitate colonisation in the challenging host environment or the avoidance of host immune detection and antibiotic attack. The clinical impacts of many of these adaptations have been comprehensively reviewed by Hauser et al. [290]. Hypermutable bacteria have an increased mutation rate of up to 1000 fold. It has been well established that hypermutable populations have been identified among CF pathogens, including $P$. aeruginosa, $H$. influenzae and $S$. aureus, contributing to their adaptability. This hypermutability of CF pathogens is illustrated by a study demonstrating that 68 genetic alterations accumulated in $P$. aeruginosa isolates from a chronically colonised CF patient over 8 years. Many of these genetic alterations were also identified in isolates from 29 other patients and were virulence genes associated with the initiation of infection which were selected against over time [30]. In a follow-up study, it was apparent that anti-microbial resistance genes were not over-represented among these hypermutated genes suggesting a more general adaptation to the CF lung [31] rather than to treatment regimens.

Phenotypic changes in $P$. aeruginosa during chronic infection have been well documented. P. aeruginosa isolated from patients with acute respiratory infection are generally non-encapsulated, expressing a variety of invasive virulence factors including flagella, type IV pili, multiple secreted toxins and degradative enzymes whereas $P$. aeruginosa isolates from chronically infected patients typically lack invasive virulence factors and convert to a mucoid phenotype during the establishment of chronic infection. This phenotype is associated with biofilm formation and resistance to phagocytosis. Phenotypic changes in Bcc isolates during the course of infection have also been described. In contrast to $P$. aeruginosa, Bcc changes from a mucoid to a non-mucoid phenotype during chronic colonisation and patients which were infected exclusively with non-mucoid Bcc had a more rapid decline in lung function than those infected with mucoid bacteria [32 $2^{\bullet \bullet}$. Bcc mucoid isolates also lost expression of virulence factors and acquired a mutation in a quorum sensing (QS) gene during chronic infection [33]. Furthermore, proteomic analysis of clonal B. cenocepacia variants obtained during long-term colonisation showed an increase in peptidoglycan synthesis enzymes, iron uptake and chaperone proteins in later isolates, further demonstrating the adaptation of these organisms to the lung environment [34].

S. aureus can establish infection in the CF lung by adaptation using some of the strategies already discussed for $P$. aeruginosa. It also forms robust biofilms and ica expression is upregulated under hypoxic conditions, further promoting biofilm formation in oxygen deprived regions of the CF lung [35]. Small colony variants (SCV) of $S$. aureus frequently cultured from the CF lung are associated with higher rates of intracellular invasion [11]. There is also some evidence of hypermutable strains of $S$. aureus in $\mathrm{CF}$ and similar to other successful CF pathogens, this organism also downregulates certain virulence genes during chronic infection [36]. 
All three of these CF pathogens modulate virulence mechanisms during chronic infection, however the phenotypic changes that occur in these different organisms over time are very varied and the significance of many of these changes to the establishment of infection and to CF lung disease is not fully understood.

\section{Specific strategies to evade host response}

Bacterial invasion of the epithelium may provide an effective escape from the host response or antibiotic therapy for some pathogens or maybe a host clearance mechanism for others. Whatever the consequences of bacterial uptake by epithelial cells, phagocytosis by the immune cells directs the pathogen towards death by either oxidative or non-oxidative means. In addition to biofilm formation providing resistance to phagocytosis, additional strategies are also used to overcome this host response mechanism. $P$. aeruginosa can evade phagocytosis by becoming non-motile [37]. Similarly, Staphylococcus aureus forms polysaccharide encased cells under oxygen limited conditions which confer resistance to neutrophil killing [35]. Bcc strains are inherently resistant to non-oxidative killing [38] and some Bcc strains can also survive within macrophages by inhibiting phagosomelysosome fusion [39].

Many CF pathogens disrupt epithelial integrity by opening the intracellular tight junctions, providing a possible mechanism for infiltration of pathogens within lung tissue and enabling access to receptors on the basolateral side of the epithelium, potentially provoking further inflammation. $P$. aeruginosa disrupts tight junctions relatively slowly as measured by a gradual drop in transepithelial electrical resistance and a concomitant decrease in the expression of the tight junction protein, ZO-1 within $24 \mathrm{~h}$ of infection [40]. By contrast, Bcc induces a more rapid disruption in epithelial integrity with a reduction in ZO-1 within $4 \mathrm{~h}$, suggesting that different mechanisms are involved [41]. Certain Pandoraea pulmonicola isolates also impair epithelial integrity within $4 \mathrm{~h}$ [4]. This difference in the rate of epithelial barrier disruption may be significant, since $P$. aeruginosa is not associated with septicemia in $\mathrm{CF}$ patients, while Bcc-associated septicemia has been widely reported.

\section{Quorum sensing facilitates adaptation}

Virulence of many pathogens is regulated by QS signaling systems that are dependent on bacterial cell density. Three QS systems operate in $P$. aeruginosa, las, rhl and pqs which function in an interconnecting network, facilitating co-operation and cheating within $P$. aeruginosa populations $\left[42^{\bullet}\right]$. The virulence gene regulation of $P$. aeruginosa is well studied and many virulence determinants including motility and biofilm formation are QS dependent as reviewed recently [43,44]. QS signaling molecules also appear to have direct effects on host cells via calcium signaling. It was recently shown that the
$P$. aeruginosa QS autoinducer molecule 3O-C12-HSL dramatically disrupted lung epithelial integrity by calcium-mediated alterations in tight junction protein interactions [45]. QS also regulates many $S$. aureus virulence genes as recently reviewed by Goerke and Wolz (2010) [36]. In particular, the agr QS system has a negative effect on $S$. aureus biofilm formation. During chronic infection, QS mutations occur to varying extents in $\mathrm{CF}$ pathogens. Although the diversity of QS deficient variants of $P$. aeruginosa in the CF lung is high [46], and agr $S$. aureus mutants are regularly isolated from CF lungs, QS mutations were infrequently observed among clinical $B$. cenocepacia isolates and those with QS mutations were growth impaired relative to wild type [47]. These findings suggests significant species differences in these regulatory networks and again highlight that CF pathogens implement different strategies to establish chronic infections.

\section{Variable oxygen concentrations and low iron}

Successful CF pathogens have adapted to survive in a range of oxygen concentrations found in the CF lung. $P$. aeruginosa grows maximally in a microaerobic environment and the presence of cyanide in CF sputum suggests that regions of the CF lung facilitate the optimal growth of $P$. aeruginosa under microaerophilic conditions [48]. $P$. aeruginosa also adapts well to anaerobic niches in the lung and $P$. aeruginosa $\mathrm{CF}$ isolates have increased transcription of genes involved in both denitrification and fermentation [49]. Bcc are also cyanogenic under biofilm and colonial growth conditions [50]. Therefore, both of these pathogenic species are capable of adapting to varied oxygen availability which is fundamental to their survival and proliferation in the CF lung.

In addition to oxygen, a key element for the survival of all pathogens is iron. Pathogens overcome the iron depleted environment in the lung, primarily by the production of iron chelating siderophores, transported across the membrane via specific receptors. Pyoverdine and pyochelin are both produced by $P$. aeruginos $a$ and levels of intracellular iron in this species affect surface motility and biofilm maturation. Production of siderophores by Bcc are reviewed by Thomas (2007) [51]. Ornibactin is the most significant siderophore produced by Bcc organisms and has been implicated in their survival in a mouse model [52]. In addition to the production of siderophores, some $\mathrm{CF}$ pathogens can also use exogenous siderophores from other species to acquire iron. P. aeruginosa's iron-regulated genes, respond to ornibactin from Burkholderia [53] and over thirty different siderophore receptors have been identified in $P$. aeruginosa strains as reviewed in [54] facilitating the uptake of exogenous siderophores. To counteract the iron scavenging mechanisms of invading pathogens, the host secretes the siderophore binding protein, siderocalin and phagocytes also acquire iron from some bacterial siderophores. However, recent evidence of 
increased expression of siderophore receptors by clonal $B$. cenocepacia variants obtained during long-term colonisation [34] suggests an adaptive strategy by this pathogen to overcome any host response to limit iron availability.

\section{Adaptation to high concentrations of antibiotics}

Most CF pathogens are notoriously difficult to eliminate with antibiotic therapy. Many $\mathrm{CF}$ isolates are more resistant to antibiotics in the biofilm mode of growth $[55,56]$. Slow bacterial growth and reduced metabolic activity, in addition to the physical barrier of the biofilm matrix all contribute to this phenomenon. In addition to biofilm formation, CF pathogens also undergo mutations of antibiotic target sites and proactively eliminate antibiotics by enzymatic cleavage as in the case of $\beta$-lactam antibiotics or by efflux mechanisms. Four multidrug efflux systems are reported to play a role in the antibiotic resistance of $P$. aeruginosa CF isolates with the MexXY-OprM system playing the predominant role in aminoglycoside resistance [57]. A recent study of the genetic pathways involved in Bcc antibiotic resistance revealed that they were also multifactorial and include beta lactamases, novel efflux pumps, a phenylacetic acid degradative pathway and phosphohydrolases [58]. Both P. aeruginosa and Bcc therefore have an array of strategies which allow them to tolerate high doses of antibiotics delivered to the lung. The challenge in developing novel antimicrobial therapies is to identify new targets which can by-pass or overcome the array of bacterial resistance mechanisms.

\section{Future directions}

The key to understanding the complex interactions between host and pathogen is having relevant models for their study. However, the development of representative $\mathrm{CF}$ animal models has been challenging. Mouse models have been limited as CF-mice generally exhibit a normal lung physiology without mucous plug obstruction. More recently developed CF-pig and CF-ferret models demonstrated mucous gland secretions that resemble those of human CF [59,60]. The lungs of newborn CF-piglets showed evidence of airway obstruction and reduced eradication of instilled bacteria [61]. CF-ferrets showed a higher abundance of bacteria in two-day old animals, but this difference was not maintained in animals that died after one week [59]. Analysis of these models continues and it may be several years before they become effective tools for host-pathogen interaction studies. Until then, many microbial pathogenesis studies in $\mathrm{CF}$ will continue to be performed with immortalised lung epithelial cells, ideally in the more physiologically relevant polarised format. A more relevant approach, albeit of scarce supply, is using primary cultures from explanted lungs of $\mathrm{CF}$ patients at transplant. The difficulties with this model were recently highlighted by Brodlie et al., where many cultures were overgrown by bacteria which colonised the patients [62]. Those successful bacteria-free cultures formed a polarised epithelium, expressing phenotypes of well differentiated CF primary cells, yet this differentiated phenotype did not extend beyond two passages [62], limiting their use for detailed investigation of hostmicrobial interactions.

Finally, further research is required into the hostmicrobial interactions of the less studied CF pathogens, for example, A. xyloxidans, Pandoraea and NTM, and more importantly, inter-bacterial interactions in the polymicrobial community that persists in the CF lung.

\section{Acknowledgements}

This Centre of Applied Science for Health is supported by the PRTLI Cycle 4 (supported by the European Union Regional Development Plan, the Irish Government National Development Plan 2007-2013 and administered by the HEA in Ireland). MC and SMcC are members of the EU COST Action BM1003: Microbial cell surface determinants of virulence as targets for new therapeutics in CF.

\section{References and recommended reading}

Papers of particular interest, published within the period of review, have been highlighted as:

$$
\begin{aligned}
& \text { - of special interest } \\
& \text { • of outstanding interest }
\end{aligned}
$$

1. Boucher RC: Evidence for airway surface dehydration as the - $\quad$ initiating event in CF airway disease. J Intern Med 2007, 261:5-16.

This paper presents a clear hypothesis regarding a link between the CFTR defect, mucous production and susceptibility of CF lung to colonisation by pathogens.

2. Lipuma JJ: The changing microbial epidemiology in cystic - fibrosis. Clin Microbiol Rev 2010, 23:299-323.

This review describes the current epidemiology of respiratory tract infection in CF and the changes which have occurred in recent years. Important features of common and emerging pathogens are discussed and the factors that restrict the interpretation of data for monitoring microbial epidemiology in CF are also highlighted.

3. Hansen CR, Pressler T, Nielsen KG, Jensen PO, Bjarnsholt T, Hoiby N: Inflammation in Achromobacter xylosoxidans infected cystic fibrosis patients. J Cyst Fibros 2010, 9:51-58.

4. Costello A, Herbert G, Fabunmi L, Schaffer K, Kavanagh KA Caraher EM, Callaghan M, McClean S: Virulence of an emerging respiratory pathogen, genus Pandoraea, in vivo and its interactions with lung epithelial cells. J Med Microbiol 2011, 60:289-299.

5. Esther CR Jr, Esserman DA, Gilligan P, Kerr A, Noone PG: Chronic Mycobacterium abscessus infection and lung function decline in cystic fibrosis. J Cyst Fibros 2010, 9:117-123.

6. Dalboge CS, Hansen CR, Pressler T, Hoiby N, Johansen HK: Chronic pulmonary infection with Stenotrophomonas maltophilia and lung function in patients with cystic fibrosis. $J$ Cyst Fibros 2011, 10:318-325.

7. Tunney MM, Field TR, Moriarty TF, Patrick S, Doering G Muhlebach MS, Wolfgang MC, Boucher R, Gilpin DF, McDowell A et al.: Detection of anaerobic bacteria in high numbers in sputum from patients with cystic fibrosis. Am J Respir Crit Care Med 2008, 177:995-1001.

8. Tunney MM, Klem ER, Fodor AA, Gilpin DF, Moriarty TF, McGrath SJ, Muhlebach MS, Boucher RC, Cardwell C, Doering G et al.: Use of culture and molecular analysis to determine the effect of antibiotic treatment on microbial community diversity and abundance during exacerbation in patients with cystic fibrosis. Thorax 2011, 66:679-684.

9. Schroeder TH, Lee MM, Yacono PW, Cannon CL, Gerceker AA, Golan DE, Pier GB: CFTR is a pattern recognition molecule that 
extracts Pseudomonas aeruginosa LPS from the outer membrane into epithelial cells and activates NF-kappa B translocation. Proc Natl Acad Sci USA 2002, 99:6907-6912.

10. Taylor JB, Hogue LA, LiPuma JJ, Walter MJ, Brody SL, Cannon CL: Entry of Burkholderia organisms into respiratory epithelium: CFTR, microfilament and microtubule dependence. J Cyst Fibros 2010, 9:36-43.

11. Mitchell G, Grondin G, Bilodeau G, Cantin AM, Malouin F: Infection of polarized airway epithelial cells by normal and small-colony variant strains of Staphylococcus aureus is increased in cells with abnormal CFTR function and is influenced by NF-\{kappa\}B. Infect Immun 2011, 79:3541-3551.

12. McClean S, Callaghan M: Burkholderia cepacia complex: epithelial cell-pathogen confrontations and potential for therapeutic intervention. J Med Microbiol 2009, 58:1-12.

13. Mullen T, Callaghan M, McClean S: Invasion of Burkholderia cepacia complex isolates into lung epithelial cells involves glycolipid receptors. Microb Pathog 2010, 49:381-387.

14. Chemani C, Imberty A, de Bentzmann S, Pierre M, Wimmerova M, Guery BP, Faure K: Role of LecA and LecB lectins in Pseudomonas aeruginosa-induced lung injury and effect of carbohydrate ligands. Infect Immun 2009, 77:2065-2075.

15. Reeves EP, Bergin DA, Murray MA, McElvaney NG: The involvement of glycosaminoglycans in airway disease associated with cystic fibrosis. ScientificWorldJournal 2011, 11:959-971.

16. Teichgraber V, Ulrich M, Endlich N, Riethmuller J, Wilker B, De

-. Oliveira-Munding CC, van Heeckeren AM, Barr ML, von Kurthy G, Schmid KW et al:: Ceramide accumulation mediates inflammation, cell death and infection susceptibility in cystic fibrosis. Nat Med 2008, 14:382-391.

This paper provides a mechanism for the role of ceramide accumulation in $\mathrm{CF}$ chronic lung disease, and demonstrates that inhibition of acid sphingomylelinse with amitryptilline resulted in reduced $P$. aeruginosa colonisation of mice.

17. Becker KA, Riethmuller J, Luth A, Doring G, Kleuser B, Gulbins E: Acid sphingomyelinase inhibitors normalize pulmonary ceramide and inflammation in cystic fibrosis. Am J Respir Cell Mol Biol 2010, 42:716-724.

18. Chun J, Prince A: TLR2-induced calpain cleavage of epithelial junctional proteins facilitates leukocyte transmigration. Cell Host Microbe 2009, 5:47-58.

19. Del Porto P, Cifani N, Guarnieri S, Di Domenico EG, Mariggio MA, Spadaro F, Guglietta S, Anile M, Venuta F, Quattrucci S et al. Dysfunctional CFTR alters the bactericidal activity of human macrophages against Pseudomonas aeruginosa. PLOS ONE 2011, 6:e19970.

20. Henke MO, John G, Rheineck C, Chillappagari S, Naehrlich L, Rubin BK: Serine proteases degrade airway mucins in cystic fibrosis. Infect Immun 2011, 79:3438-3444.

21. Cosgrove S, Chotirmall SH, Greene CM, McElvaney NG: Pulmonary proteases in the cystic fibrosis lung induce interleukin 8 expression from bronchial epithelial cells via a heme/meprin/epidermal growth factor receptor/Toll-like receptor pathway. J Biol Chem 2011, 286:7692-7704.

22. Kaza SK, McClean S, Callaghan M: IL-8 released from human lung epithelial cells induced by cystic fibrosis pathogens Burkholderia cepacia complex affects the growth and intracellular survival of bacteria. Int J Med Microbiol 2010, 301:26-33.

23. Roderfeld M, Rath T, Schulz R, Seeger W, Tschuschner A, Graf J, Roeb E: Serum matrix metalloproteinases in adult CF patients: relation to pulmonary exacerbation. J Cyst Fibros 2009, 8:338-347.

24. Gaggar A Li Y, Weathington N, Winkler M, Kong M, Jackson P, Blalock JE, Clancy JP: Matrix metalloprotease-9 dysregulation in lower airway secretions of cystic fibrosis patients. $\mathrm{Am} \mathrm{J}$ Physiol Lung Cell Mol Physiol 2007, 293:L96-L104.

25. Wright C, Pilkington R, Callaghan M, McClean S: Activation of MMP-9 by human lung epithelial cells in response to the cystic fibrosis associated pathogen $B$. cenocepacia, reduced wound healing in vitro. Am J Physiol 2011, 301:L575-L586.

26. Coakley RD, Sun $\mathrm{H}$, Clunes LA, Rasmussen JE, Stackhouse JR, Okada SF, Fricks I, Young SL, Tarran R: 17beta-Estradiol inhibits $\mathrm{Ca2+-dependent} \mathrm{homeostasis} \mathrm{of} \mathrm{airway} \mathrm{surface} \mathrm{liquid} \mathrm{volume}$ in human cystic fibrosis airway epithelia. J Clin Invest 2008, 118:4025-4035

27. Wang Y, Cela E, Gagnon S, Sweezey NB: Estrogen aggravates inflammation in Pseudomonas aeruginosa pneumonia in cystic fibrosis mice. Respir Res 2010, 11:166.

28. Dubin PJ, Kolls JK: IL-23 mediates inflammatory responses to mucoid Pseudomonas aeruginosa lung infection in mice. $\mathrm{Am} \mathrm{J}$ Physiol Lung Cell Mol Physiol 2007, 292:L519-L528.

29. Hauser AR, Jain M, Bar-Meir M, McColley SA: Clinical

-. significance of microbial infection and adaptation in cystic fibrosis. Clin Microbiol Rev 2011, 24:29-70.

This is an excellent comprehensive review on the adaptations that CF pathogens undergo while establishing a chronic infection and clearly links these to the relevant clinical data, highlighting the clinical impact of each adaptation.

30. Smith EE, Buckley DG, Wu Z, Saenphimmachak C, Hoffman LR, D'Argenio DA, Miller SI, Ramsey BW, Speert DP, Moskowitz SM et al.: Genetic adaptation by Pseudomonas aeruginosa to the airways of cystic fibrosis patients. Proc Natl Acad Sci USA 2006, 103:8487-8492.

31. Mena A, Smith EE, Burns JL, Speert DP, Moskowitz SM, Perez JL, Oliver A: Genetic adaptation of Pseudomonas aeruginosa to the airways of cystic fibrosis patients is catalyzed by hypermutation. J Bacteriol 2008, 190:7910-7917.

32. Zlosnik JE, Costa PS, Brant R, Mori PY, Hird TJ, Fraenkel MC

- Wilcox PG, Davidson AG, Speert DP: Mucoid and nonmucoid Burkholderia cepacia complex bacteria in cystic fibrosis infections. Am J Respir Crit Care Med 2011, 183:67-72.

This article and the subsequent one [33] challenged the previously held theory that mucoid Bcc isolates, like mucoid $P$ aeruginosa were associated with increased virulence. It clearly demonstrates that CF patients colonised exclusively with non-mucoid Bcc showed a more rapid decline in lung function. They also demonstrated that the phenotypic switch from mucoid to non-mucoid could be induced by antibiotics

33. Zlosnik JE, Speert DP: The role of mucoidy in virulence of bacteria from the Burkholderia cepacia complex: a systematic proteomic and transcriptomic analysis. J Infect Dis 2010 202:770-781

34. Madeira A, Santos PM, Coutinho CP, Pinto-de-Oliveira A, SaCorreia I: Quantitative proteomics (2-D DIGE) reveals molecular strategies employed by Burkholderia cenocepacia to adapt to the airways of cystic fibrosis patients under antimicrobial therapy. Proteomics 2011, 11:1313-1328.

35. Ulrich M, Bastian M, Cramton SE, Ziegler K, Pragman AA, Bragonzi A, Memmi G, Wolz C, Schlievert PM, Cheung A et al.: The staphylococcal respiratory response regulator SrrAB induces ica gene transcription and polysaccharide intercellular adhesin expression, protecting Staphylococcus aureus from neutrophil killing under anaerobic growth conditions. $\mathrm{Mol}$ Microbiol 2007, 65:1276-1287.

36. Goerke C, Wolz C: Adaptation of Staphylococcus aureus to the cystic fibrosis lung. Int $J$ Med Microbiol 2010, 300:520-525.

37. Amiel E, Lovewell RR, O'Toole GA, Hogan DA, Berwin B: Pseudomonas aeruginosa evasion of phagocytosis is mediated by loss of swimming motility and is independent of flagellum expression. Infect Immun 2010, 78:2937-2945.

38. Sousa SA, Ulrich M, Bragonzi A, Burke M, Worlitzsch D, Leitao JH, Meisner C, Eberl L, Sa-Correia I, Doring G: Virulence of Burkholderia cepacia complex strains in gp91(phox-/-) mice. Cell Microbiol 2007, 9:2817-2825.

39. Saijan US, Yang JH, Hershenson MB, LiPuma JJ: Intracellular trafficking and replication of Burkholderia cenocepacia in human cystic fibrosis airway epithelial cells. Cell Microbiol 2006, 8:1456-1466.

40. Halldorsson S, Gudjonsson T, Gottfredsson M, Singh PK, Gudmundsson GH, Baldursson O: Azithromycin maintains 
airway epithelial integrity during Pseudomonas aeruginosa infection. Am J Respir Cell Mol Biol 2010, 42:62-68.

41. Duff C, Murphy PG, Callaghan M, McClean S: Differences in invasion and translocation of Burkholderia cepacia complex species in polarised lung epithelial cells in vitro. Microb Pathog 2006, 41:183-192.

42. Wilder CN, Diggle SP, Schuster M: Cooperation and cheating in - Pseudomonas aeruginosa: the roles of the las, rhl and pqs quorum-sensing systems. ISME J 2011, 5:1332-1343.

This paper provides evidence of the evolution of QS mutants from wildtype in $P$. aeruginosa. Using QS regulatory and signal mutants, some of the interactions of the interconnected QS networks within a single species are defined, and suggest a mechanism for the prevalence of naturally occurring QS mutants.

43. Winstanley C, Fothergill JL: The role of quorum sensing in chronic cystic fibrosis Pseudomonas aeruginosa infections. FEMS Microbiol Lett 2009, 290:1-9.

44. Williams $P$, Camara $M$ : Quorum sensing and environmental adaptation in Pseudomonas aeruginosa: a tale of regulatory networks and multifunctional signal molecules. Curr Opin Microbiol 2009, 12:182-191.

45. Vikstrom E, Bui L, Konradsson P, Magnusson KE: Role of calcium signalling and phosphorylations in disruption of the epithelial junctions by Pseudomonas aeruginosa quorum sensing molecule. Eur J Cell Biol 2010, 89:584-597.

46. Wilder CN, Allada G, Schuster M: Instantaneous within-patient diversity of Pseudomonas aeruginosa quorum-sensing populations from cystic fibrosis lung infections. Infect Immun 2009, 77:5631-5639.

47. McKeon SA, Nguyen DT, Viteri DF, Zlosnik JE, Sokol PA Functional quorum sensing systems are maintained during chronic Burkholderia cepacia complex infections in patients with cystic fibrosis. J Infect Dis 2011, 203:383-392.

48. Ryall B, Davies JC, Wilson R, Shoemark A, Williams HD: Pseudomonas aeruginosa, cyanide accumulation and lung function in CF and non-CF bronchiectasis patients. Eur Respir $J$ 2008, 32:740-747.

49. Hoboth C, Hoffmann R, Eichner A, Henke C, Schmoldt S, Imhof A, Heesemann J, Hogardt M: Dynamics of adaptive microevolution of hypermutable Pseudomonas aeruginosa during chronic pulmonary infection in patients with cystic fibrosis. J Infect Dis 2009, 200:118-130.

50. Ryall B, LeeX, Zlosnik JE, Hoshino S, Williams HD: Bacteria of the Burkholderia cepacia complex are cyanogenic under biofilm and colonial growth conditions. BMC Microbiol 2008, 8:108.
51. Thomas MS: Iron acquisition mechanisms of the Burkholderia cepacia complex. Biometals 2007, 20:431-452.

52. Visser MB, Majumdar S, Hani E, Sokol PA: Importance of the ornibactin and pyochelin siderophore transport systems in Burkholderia cenocepacia lung infections. Infect Immun 2004, 72:2850-2857.

53. Weaver VB, Kolter R: Burkholderia spp. alter Pseudomonas aeruginosa physiology through iron sequestration. $J$ Bacteriol 2004, 186:2376-2384.

54. Cornelis $\mathrm{P}$, Matthijs $\mathrm{S}$, Van Oeffelen L: Iron uptake regulation in Pseudomonas aeruginosa. Biometals 2009, 22:15-22.

55. Dales L, Ferris W, Vandemheen K, Aaron SD: Combination antibiotic susceptibility of biofilm-grown Burkholderia cepacia and Pseudomonas aeruginosa isolated from patients with pulmonary exacerbations of cystic fibrosis. Eur J Clin Microbiol Infect Dis 2009, 28:1275-1279.

56. Caraher E, Reynolds G, Murphy P, McClean S, Callaghan M: Comparison of antibiotic susceptibility of Burkholderia cepacia complex organisms when grown planktonically or as biofilm in vitro. Eur J Clin Microbiol Infect Dis 2007, 26:213-216.

57. Vettoretti L, Plesiat P, Muller C, El Garch F, Phan G, Attree I, Ducruix A, Llanes C: Efflux unbalance in Pseudomonas aeruginosa isolates from cystic fibrosis patients. Antimicrob Agents Chemother 2009, 53:1987-1997.

58. Sass A, Marchbank A, Tullis E, Lipuma JJ, Mahenthiralingam E: Spontaneous and evolutionary changes in the antibiotic resistance of Burkholderia cenocepacia observed by global gene expression analysis. BMC Genomics 2011, 12:373.

59. Sun $X$, Sui H, Fisher JT, Yan Z, Liu X, Cho HJ, Joo NS, Zhang $Y$, Zhou W, Yi Y et al.: Disease phenotype of a ferret CFTRknockout model of cystic fibrosis. J Clin Invest 2010, 120:3149-3160.

60. Joo NS, Cho HJ, Khansaheb M, Wine JJ: Hyposecretion of fluid from tracheal submucosal glands of CFTR-deficient pigs. $J$ Clin Invest 2010, 120:3161-3166.

61. Stoltz DA, Meyerholz DK, Pezzulo AA, Ramachandran S, Rogan MP, Davis GJ, Hanfland RA, Wohlford-Lenane C, Dohrn CL, Bartlett JA et al.: Cystic fibrosis pigs develop lung disease and exhibit defective bacterial eradication at birth. Sci Transl Med 2010, 2:29ra31.

62. Brodlie M, McKean MC, Johnson GE, Perry JD, Nicholson A, Verdon B, Gray MA, Dark JH, Pearson JP, Fisher AJ et al.: Primary bronchial epithelial cell culture from explanted cystic fibrosis lungs. Exp Lung Res 2010, 36:101-110. 